\title{
Talking about homosexuality: Lessons learned from 1949
}

Catherine H. Mercer \& Anne M. Johnson

'The problem of the homosexual with venereal disease' by F. G. Macdonald, a venereologist at London's Queen Mary's Hospital, was published in 1949 in the British Journal of Venereal Diseases, the forerunner to Sexually Transmitted Infections.[1] While the language Macdonald used to describe same-sex behaviour: "abnormality", "troubles", "the condition", is a far cry from that which we are now familiar, it is important to recall that he was writing at a time when homosexuality was regarded as a felony and would be for some years to come.[2] In this respect, his underlying tone is actually rather sympathetic and liberal for 1949, including, for example, promoting the use of "less offensive" terms for men who have sex with men (MSM).

There are interesting parallels to be drawn between Macdonald's courageous commentary and the endeavours of Britain's National Surveys of Sexual Attitudes and Lifestyles (Natsal), in addition to the challenge of reliably estimating the population prevalence of same-sex behaviour. Since their inception in the late 1980s, the Natsal studies have (also) been careful to use non-judgemental and non-stigmatising language, both in the reporting of findings but in data collection so as to maximise people's willingness to report sensitive behaviours.[3] While Macdonald recognised the spectrum, fluidity, and temporality of sexual behaviour and its distinction from sexual identity, it was only in the most recent Natsal survey undertaken 2010-12 that participants were asked to report how they described their sexual identity (in addition to their behaviour).[4,5] This reflects Natsal's focus especially in the initial round of the survey - to capture what people do rather than how they describe themselves, recognising, as Macdonald did, that sexual identity should not be relied upon to indicate ST/HIV risk. Macdonald's insights therefore continue to challenge our thinking as they did in the 1940s.

\section{References:}

[1] Macdonald FG. The Problem of the Homosexual. Br J Vener Dis 1949 25: 13-15.

[2] Sexual Offences Act 1967. http://www.legislation.gov.uk/ukpga/1967/60/contents. Accessed: 4 April 2017.

[3] Johnson AM, Wadsworth J, Field J, Wellings K, Anderson RM. Surveying sexual attitudes. Nature, 1990;343(6254):109.

[4] Erens B, Phelps A, Cifton S, Mercer CH, Tanton C, Hussey D, Sonnenberg P, Macdowall W, Field N, Datta J, Mitchell K, Copas AJ, Jones K, Wellings K, Johnson AM. Methodology of the third British National Survey of Sexual Attitudes and Lifestyles (Natsal-3). Sex Transm Inf, 2013; doi:10.1136/sextrans-2013-051359.

[5] Mercer CH, Tanton C, Prah P, Wellings K, Erens B, Sonnenberg P, Cifton S, Macdowall W, Lewis R, Field N, Datta J, Copas AJ, Phelps A, Johnson AM. Changes in sexual attitudes and lifestyles in Britain through the life course and over time: findings from the National Surveys of Sexual Attitudes and Lifestyles (Natsal). Lancet, 2013; 382: 1780-1794. 